\title{
miR-223-3p/TIAL1 interaction is involved in the mechanisms associated with the neuroprotective effects of dexmedetomidine on hippocampal neuronal cells in vitro
}

\author{
QI WANG, HONGMEI YU, HONG YU, MEINA MA, YALI MA and RUI LI \\ Department of Anesthesiology, Cangzhou Central Hospital, Cangzhou, Hebei 061001, P.R. China
}

Received March 10, 2017; Accepted May 15, 2018

DOI: $10.3892 / \mathrm{mmr} .2018 .9742$

\begin{abstract}
Dexmedetomidine (DEX), an $\alpha 2$ adrenoceptor agonist, is a commonly used anesthetic drug in surgical procedures. Previous studies have indicated that DEX exerts neuroprotective effects. However, the molecular mechanism underlying this process remains to be elucidated. The present study investigated a potential implication of microRNA (miR)-223-3p in the DEX-induced anti-oxidative effect on neuronal cells. The results indicated that following hydrogen peroxide $\left(\mathrm{H}_{2} \mathrm{O}_{2}\right)$-mediated induction of oxidative stress, the viability of human hippocampal neuronal cells was markedly decreased, as determined by an MTT assay. In addition, treatment with $\mathrm{H}_{2} \mathrm{O}_{2}$ induced cell apoptosis, the release of lactate dehydrogenase, accumulation of intracellular calcium, phosphorylation of calmodulin-2, and production of malondialdehyde and reactive oxygen species. Furthermore, treatment with $\mathrm{H}_{2} \mathrm{O}_{2}$ inhibited the expression of mir-223-3p and enhanced the expression of its target cytotoxic granule associated RNA binding protein like 1 (TIAL1), and these effects were reversed by treatment with DEX. Mechanistic studies demonstrated that the 3'-untranslated region of TIAL1 is a direct target of mir-223-3p. The results of the present study demonstrated that DEX may induce its neuroprotective effects by regulating the interaction between miR-223-3p and TIAL1. Therefore, the manipulation of miR-223-3p/TIAL1 interaction may be involved in the neuroprotective effects of DEX.
\end{abstract}

\section{Introduction}

Dexmedetomidine (DEX) is an anesthetic agent, which, due to its ability to produce a rapid and controlled sedative

Correspondence to: Mr. Qi Wang, Department of Anesthesiology, Cangzhou Central Hospital, 16 Xinhua West Road, Cangzhou, Hebei 061001, P.R. China

E-mail: bravo118@sina.com

Key words: dexmedetomidine, oxidative stress, microRNA-223-3p, TIA1 cytotoxic granule-associated RNA binding protein-like 1, neuronal cells response and few side effects, is used in medical procedures for long-lasting sedation of patients (1-3). Previous studies indicated that DEX can prevent brain ischemia, lung ischemia-reperfusion injury, acute kidney injury, intestinal ischemia-reperfusion injury and myocardial ischemia, alleviate intracellular accumulation of reactive oxygen species (ROS) and prevent apoptotic cell death in vivo (1-12). A recent study demonstrated that DEX exerts its neuroprotective effects on apoptotic, calcium and oxidative stress signaling pathways through regulation of the transient receptor potential cation channel, subfamily $\mathrm{M}$, member 2 and transient receptor potential cation channel subfamily $\mathrm{V}$ member 1 in rats (13). Neuroprotection of DEX has also been associated with the inhibition of the pro-inflammatory nuclear factor- $\kappa \mathrm{B}$ and interleukin- $1 \beta$ signaling pathways $(1,14)$. Similarly, another in vivo study demonstrated that DEX protects from cerebral ischemia/reperfusion injury in rats via regulation of the phosphatidylinositol 4,5-bisphosphate 3-kinase/RAC-alpha serine/threonine-protein kinase and extracellular signal-regulated kinase (ERK)1/2 signaling pathways (15). However, the molecular mechanisms underlying neuroprotective properties of DEX remain to be elucidated.

MicroRNAs (miRs), small non-coding gene regulatory RNAs, serve neuroprotective roles by regulating physiological or pathological cellular processes involving cell invasion and migration, and responses to stress and apoptosis (16-21). Previous studies indicated that miR-223 prevents alcohol-induced liver injury in neutrophils by inhibiting the interleukin-6-p47phox-ROS signaling pathway (22). It has also been demonstrated that CXCR $2 / \mathrm{miR}-223-3 \mathrm{p} / \mathrm{miR}-27 \mathrm{~b}$ pathway protects from ischemic cerebral injury (23). However, whether miR-223-3p serves a role in the oxidative stress-associated brain injury remains to be elucidated. In addition, to the best of the authors knowledge, the association between miR-223-3p and the neuroprotective effect of DEX has not yet been reported.

TIA1 cytotoxic granule associated RNA binding protein like 1 (TIAL1) is a gene encoding a member of an RNA-binding protein family that regulates a set of cellular activities, including splicing and regulation of translation and apoptosis. The role of TIAL1 in cytotoxicity remains to be elucidated, but due to its apoptotic and RNA-binding properties, the authors of the present study hypothesized that 
modulation of TIAL1 can mediate the neuroprotective effects of DEX on hippocampal cells in an miR-dependent manner.

Therefore, the present study aimed to investigate the effect of oxidative stress on the expression of miR-223-3p in hippocampal neurons and determine whether the neuroprotective activity of DEX is mediated by the regulation of miR-223-3p. The results demonstrated that miR-223-3p was significantly downregulated as a response to oxidative injury. Furthermore, expression of miR-223-3p was significantly upregulated following treatment with DEX and overexpression of miR-223-3p using miR-223-3p mimics resulted in neuroprotection. Therefore, the results of the present study indicated that DEX-mediated upregulation of miR-223-3p is involved in the neuroprotective effect of DEX.

\section{Materials and methods}

Cell culture. Human Neurons-hippocampal (HN-h) primary cells (cat. no. 1540) were purchased from ScienCell Research Laboratories, Inc. (San Diego, CA, USA). Cells were cultured in a neuronal medium (cat. no. 1521; ScienCell Research Laboratories, Inc.) in an incubator at $37^{\circ} \mathrm{C}, 95 \%$ humidity and $5 \% \mathrm{CO}_{2}$ for $48 \mathrm{~h}$, according to the manufacturer's protocol. A total of 2.5, 5, 10 or $20 \mu \mathrm{M}$ DEX (Santa Cruz Biotechnology, Inc., Dallas, TX, USA) was dissolved in $0.2 \%$ final concentration dimethyl sulfoxide (DMSO) and incubated for $1 \mathrm{~h}$. Subsequently, hydrogen peroxide $\left(\mathrm{H}_{2} \mathrm{O}_{2}\right.$; Sigma-Aldrich; Merck KGaA, Darmstadt, Germany) was added to each sample to a $200 \mu \mathrm{M}$ final concentration.

Cell viability. MTT assay was used to evaluate the viability of HN-h cells. Following a 48-h incubation, $20 \mu \mathrm{l}$ MTT reagent $(5 \mathrm{mg} / \mathrm{ml})$ was added to the culture and further incubated for $4 \mathrm{~h}$. Supernatants were discarded and replaced with $150 \mu \mathrm{l}$ $\mathrm{DMSO} /$ well to solubilize the formazan crystals in viable cells. The absorbance was measured at a wavelength of $570 \mathrm{~nm}$ using a spectrophotometer.

Apoptosis assay. Cell apoptosis was determined using an Annexin V/propidium iodide (PI) assay. Cells were collected by centrifugation for $5 \mathrm{~min}$ at $200 \mathrm{x} \mathrm{g}$ and $4^{\circ} \mathrm{C}$, rinsed twice using $1 \mathrm{X}$ PBS and resuspended in $1 \mathrm{X}$ binding buffer (BD Biosciences, Franklin Lakes, NJ, USA) at a concentration of $1 \times 10^{6}$ cells $/ \mathrm{ml}$. Cells were incubated with a fluorescein isothiocyanate labeled anti-Annexin $\mathrm{V}$ antibody ( $5 \mu \mathrm{l}$; eBioscience; Thermo Fisher Scientific, Inc., Waltham, MA, USA) for $15 \mathrm{~min}$ at room temperature. Following washing with Annexin V binding buffer, cells were resuspended in $200 \mu \mathrm{l}$ binding buffer. PI staining solution (5 $\mu \mathrm{l}$; eBioscience; Thermo Fisher Scientific, Inc.) was then added for 5 min and cells were analyzed using a BD Accuri C6 flow cytometer (BD Biosciences) within $1 \mathrm{~h}$.

Lipid peroxidation assay. To evaluate the malondialdehyde (MDA) content, a Lipid Peroxidation (MDA) Assay kit (cat. no. ab118970; Abcam, Cambridge, UK) was used according to the manufacturer's protocol. A total of $1 \times 10^{6}$ cells were homogenized on ice in $300 \mu 1$ MDA Lysis Buffer with $3 \mu 1100 \mathrm{X}$ butylated hydroxytoluene and centrifuged at $13,000 \mathrm{x} \mathrm{g}$ and $4^{\circ} \mathrm{C}$ for $10 \mathrm{~min}$ to remove insoluble material.
Subsequently, $200 \mu 1$ supernatant from each homogenized sample was transferred to a microcentrifuge tube and $600 \mu \mathrm{l}$ TBA solution was added/sample. Following incubation at $95^{\circ} \mathrm{C}$ for $60 \mathrm{~min}$ and cooling to room temperature using an ice bath for $10 \mathrm{~min}$, the $200 \mu \mathrm{l}$ reaction mixture was transferred into a 96 -well microplate for colorimetric analysis. The absorbance was measured at a wavelength of $532 \mathrm{~nm}$ and MDA levels were calculated using standard curve analysis according to the manufacturer's protocol.

Determination of lactate dehydrogenase $(\mathrm{LDH})$ levels. The Colorimetric Lactate Dehydrogenase (LDH) Activity Assay kit (cat. no. ab102526; Abcam) was used to determine LDH activity, according to the manufacturer's protocol. Cell culture medium was centrifuged at $13,000 \mathrm{x} \mathrm{g}$ and $4^{\circ} \mathrm{C}$ for $10 \mathrm{~min}$ to collect the supernatant for determination of cell-free LDH activity. A total of $1 \times 10^{6}$ cells were harvested by centrifugation at $13,000 \times \mathrm{g}$ and $4^{\circ} \mathrm{C}$ for $10 \mathrm{~min}$, washed with PBS, homogenized with three volumes of cold assay buffer and centrifuged at $4^{\circ} \mathrm{C}$ at $10,000 \mathrm{x}$ g for $15 \mathrm{~min}$ to eliminate insoluble material. The absorbance was measured at a wavelength of $450 \mathrm{~nm}$. LDH activity was estimated using a standard curve with NADH as a reference and LDH leakage was expressed as a ratio of cell-free LDH activity/total LDH activity.

Detection of ROS levels. Following seeding, control, $\mathrm{H}_{2} \mathrm{O}_{2}$ and DEX-treated cells were rinsed three times using PBS, trypsinized and centrifuged at $13,000 \mathrm{x} \mathrm{g}$ and $4^{\circ} \mathrm{C}$ for $10 \mathrm{~min}$. Subsequently, cells were harvested and incubated with diluted Dihydroethidium (Reactive Oxygen Detection kit; cat. no. S0033; Beyotime Institute of Biotechnology, Haimen, China) according to the manufacturer's protocol. Finally, the levels of ROS were evaluated by flow cytometry analysis using the BD Accuri ${ }^{\mathrm{TM}}$ C6 flow cytometer (BD Biosciences) for measurement of fluorescence levels in the FL2 channel.

Measurement of intracellular $\mathrm{Ca}^{2+}$. For the measurement of intercellular $\mathrm{Ca}^{2+}$, cells were incubated with Fluo 3-AM reagent (GeneCopoeia, Inc., Rockville, MD, USA) according to the manufacturer's protocol. Subsequently, $\mathrm{Ca}^{2+}$-dependent fluorescence intensity was measured by flow cytometry using the BD Accuri ${ }^{\mathrm{TM}}$ C6 Flow Cytometer (BD Biosciences, Franklin Lakes, NJ, USA) and 10,000 cells/sample were acquired and analyzed.

Transfection. HN-h cells $\left(5 \times 10^{4}\right.$ cells $\left./ \mathrm{cm}^{2}\right)$ were transfected with $2 \mathrm{nM}$ mir-223-3p mimic (MISSION microRNA Mimic; 5'-UGUCAGUUUGUCAAAUACCCCA-3'), miR-223-3p inhibitor (MISSION Synthetic microRNA Inhibitor; 5'-UGG GGUAUUUGACAAACUGACA-3') or their scrambled controls (all Sigma-Aldrich; Merck KGaA, Darmstadt, Germany). The expression vector pPM-C-HA-TIAL1 (Applied Biological Materials, Inc., Richmond, BC, Canada) was used for expression of TIAL1 and an empty pPM-C-HA vector served as a control. Transfection of these vectors was performed using DNAfectin Plus reagent (Applied Biological Materials, Inc.) according to the manufacturer's protocol. Reverse transcription-quantitative polymerase 
chain reaction (RT-qPCR) was used to evaluate the transfection efficiency $48 \mathrm{~h}$ after transfection prior to subsequent experiments.

Bioinformatics. The online tool TargetScan (www. targetscan.org/vert_71/) was used to predict TIAL1 mRNA 3'-untranslated region (UTR) as a target for Homo sapiens (has)-miR-223-3p.

Luciferase assay. Cells were transfected with human TIAL1-3'UTR-luciferase reporter plasmid (Promega Corporation, Madison, WI, USA) using Lipofectamine ${ }^{\circledR} 2000$ transfection reagent (Thermo Fisher Scientific, Inc.) and cultured for $48 \mathrm{~h}$. Luciferase assays were performed using a Dual-Luciferase Reporter Assay system (Promega Corporation, Madison, WI, USA) according to the manufacturer's protocol. Renilla luciferase was used for normalization (Promega Corporation). Each experiment was repeated three times in duplicate.

RT-qPCR analysis. Total RNA was extracted from cultured cells using the miRVana miRNA Isolation kit (Thermo Fisher Scientific, Inc.). Isolated RNA was reverse-transcribed into cDNA using the TaqMan MicroRNA Reverse Transcription kit (Thermo Fisher Scientific, Inc.). Subsequently, qPCR experiments were performed using hsa-miR-223-3p-specific primers (Sigma-Aldrich; Merck KGaA) and the CFX96 Touch ${ }^{\mathrm{TM}}$ Real-Time PCR Detection system (Bio-Rad Laboratories, Inc. Hercules, CA, USA) according to the manufacturer's protocol. The following thermocycling conditions were used for the PCR: $30 \mathrm{sec}$ at $95^{\circ} \mathrm{C} ; 45$ cycles of $95^{\circ} \mathrm{C}$ for $5 \mathrm{sec}$ and $58^{\circ} \mathrm{C}$ for $34 \mathrm{sec}$. The forward (F) and reverse (R) primers used for amplification were as follows: F, 5'-AATTCAGAAGAGGCA TACCTTAGA-3' and R, 5'-TTCAGGCTTGGGTTGTGT GT-3' for TIAL1; F, 5'-GCAACTAGGATGGTGTGGCT-3' and R, 5'-TCCCATTCCCCAGCTCTCATA-3' for GAPDH; F, 5'-CCACGCTCCGTGTATTTGAC-3' and R, 5'-cCGCAC TTGGGGTATTTGAC-3' for hsa-miR-223-3p; and F, 5'-CTC GCTTCGGCAGCACA-3' and R, 5'-AACGCTTCACGAATT TGCGT-3' for U6. Relative expression of a hsa-miR-223-3p was evaluated using the $2^{-\Delta \Delta \mathrm{Cq}}$ method (24) with U6 small nuclear RNA used for normalization for hsa-miR-223-3p and GAPDH used for normalization of TIAL1.

Western blotting. Total protein was extracted from cultured $\mathrm{HN}-\mathrm{h}$ cells using the radioimmunoprecipitation assay buffer (Sigma-Aldrich; Merck KGaA). Protein concentration was determined using a Bicinchoninic Acid kit. A total of $50 \mu \mathrm{g}$ protein was loaded per lane and purified by $10 \%$ SDS-PAGE, transferred to a polyvinylidene fluoride membrane and blocked with $5 \%$ skimmed milk in $0.1 \mathrm{M}$ PBS for $2 \mathrm{~h}$ at room temperature. The membranes were incubated overnight in the dark at $4{ }^{\circ} \mathrm{C}$ with the following primary antibodies at 1:1,000 dilution: Anti-TIAL1 (cat. no. ab129499), anti-Ca2 $/$ calmodulin-dependent protein kinase II (CaMKII; cat. no. ab22609), anti-CaMKII (phospho T286; cat. no. ab171095) and anti-GAPDH (cat. no. ab37168; all Abcam). The membranes were subsequently washed with PBS and incubated with horseradish peroxidase conjugated rabbit-anti-goat secondary antibodies
(1:40,000; cat. no. PI-1000; Vector Laboratories, Inc., Burlingame, CA, USA) for $120 \mathrm{~min}$ at room temperature. Finally, the membranes were washed three times in PBS and incubated with an enhanced chemiluminescence kit (Roche Diagnostics, Basel, Switzerland) for $5 \mathrm{~min}$ for visualization. Densitometry quantification was performed using Image $\mathbf{J}$ software (version $1.51 \mathrm{k}$; National Institutes of Health, Bethesda, MD, USA) and relative protein expression levels were calculated using GAPDH as a control.

Statistical analysis. Statistical analyses were performed using one-way or two-way analysis of variance followed by the Bonferroni post-hoc test in GraphPad prism software (version 6.01; GraphPad Software, Inc., La Jolla, CA, USA). Data were presented as the mean \pm standard deviation. $\mathrm{P}<0.05$ was considered to indicate a statistically significant difference.

\section{Results}

DEX protects $\mathrm{HN}$-h cells against $\mathrm{H}_{2} \mathrm{O}_{2}$-induced cytotoxicity. To investigate the neuroprotective effect of DEX on HN-h cells, cells were treated with different concentrations of $\mathrm{H}_{2} \mathrm{O}_{2}$ in the presence or absence of serial concentrations of DEX. MTT assay (Fig. 1A) indicated that $\mathrm{H}_{2} \mathrm{O}_{2}$ significantly inhibited the viability of $\mathrm{HN}$-h cells in a dose dependent manner. DEX reversed the adverse effects of $\mathrm{H}_{2} \mathrm{O}_{2}$, also in a dose-dependent manner. Flow cytometry analysis of cell apoptosis (Fig. 1B) confirmed that $\mathrm{H}_{2} \mathrm{O}_{2}$ induced apoptotic cell death. Treatment of $\mathrm{H}_{2} \mathrm{O}_{2}$-pretreated cells with DEX significantly inhibited cell apoptosis. Levels of cytotoxic markers, including LDH leakage and MDA content (Fig. 1C and D, respectively) were significantly increased in $\mathrm{H}_{2} \mathrm{O}_{2}$-treated cells, compared with the untreated cells. Treatment with DEX inhibited $\mathrm{H}_{2} \mathrm{O}_{2}$-mediated increase in LDH leakage and MDA content, in a dose dependent manner (Fig. 1C and 1D). Similarly, treatment with $\mathrm{H}_{2} \mathrm{O}_{2}$ increased ROS levels which decreased following treatment with DEX, in a dose-dependent manner (Fig. 1E). Level of intracellular calcium in $\mathrm{HN}$-h cells was significantly increased in response to treatment with $\mathrm{H}_{2} \mathrm{O}_{2}$ while DEX inhibited and significantly attenuated $\mathrm{H}_{2} \mathrm{O}_{2}$-induced $\mathrm{Ca}^{2+}$ increase, in a dose dependent manner (Fig. 1F). Western blot analysis indicated that phosphorylation of CAMII was inhibited following treatment with DEX (Fig. $1 \mathrm{G}$ and $\mathrm{H}$ ). The aforementioned results indicated that DEX protects $\mathrm{HN}$-h cells from $\mathrm{H}_{2} \mathrm{O}_{2}$ induced neurotoxicity.

DEX prevents $\mathrm{H}_{2} \mathrm{O}_{2}$-mediated downregulation of miR-223-3p expression in $H N$ - $h$ cells. In order to elucidate the involvement of miR-223-3p in the neuroprotective effect of DEX, the expression of miR-223-3p was measured in cells treated with different concentrations of DEX and $\mathrm{H}_{2} \mathrm{O}_{2}$. The results indicated that $\mathrm{H}_{2} \mathrm{O}_{2}$ and DEX inhibited and enhanced the expression of miR-223-3p, respectively, in a dose-dependent manner (Fig. 2). These observations suggested that miR-223-3p may be involved in the neuroprotective effect of DEX.

Upregulation of miR-223-3p expression is a mechanism involved in the neuroprotective effect of DEX against $\mathrm{H}_{2} \mathrm{O}_{2}$ 
A
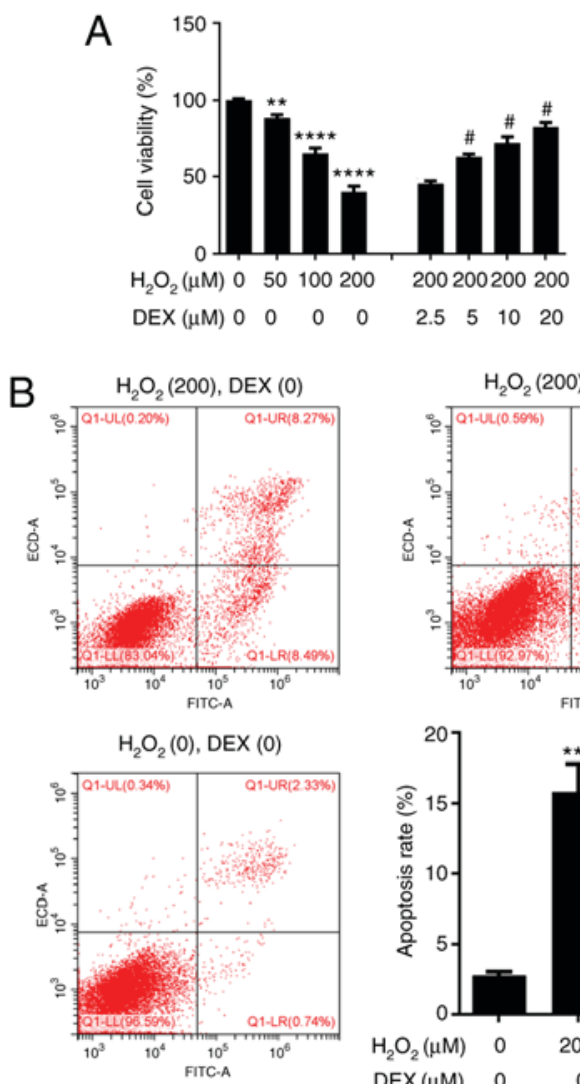

C
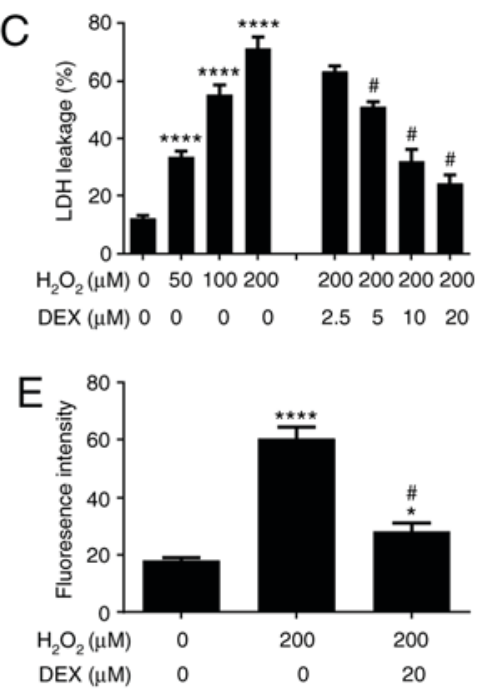

G
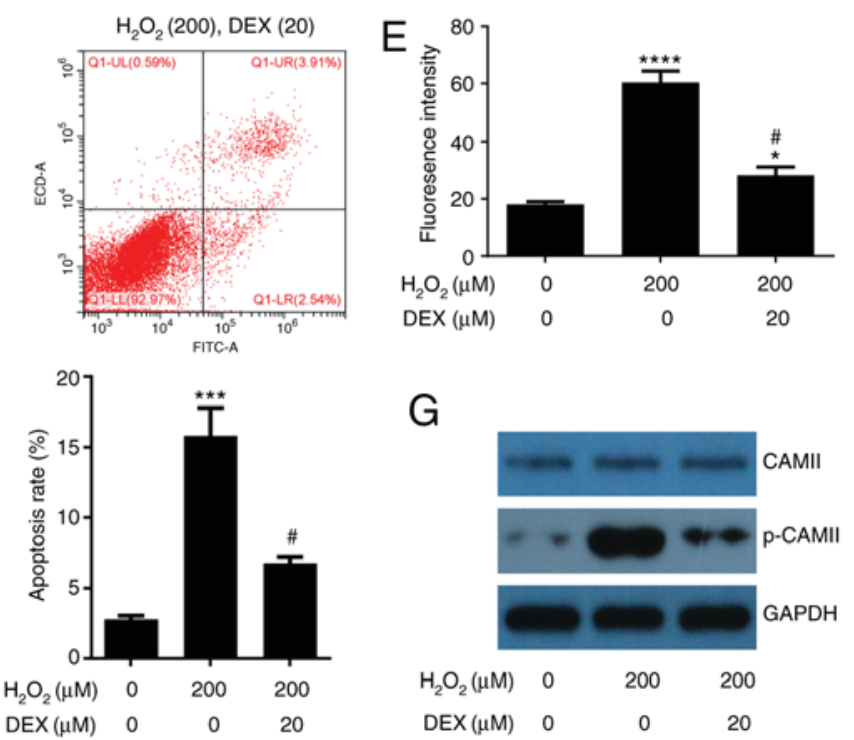
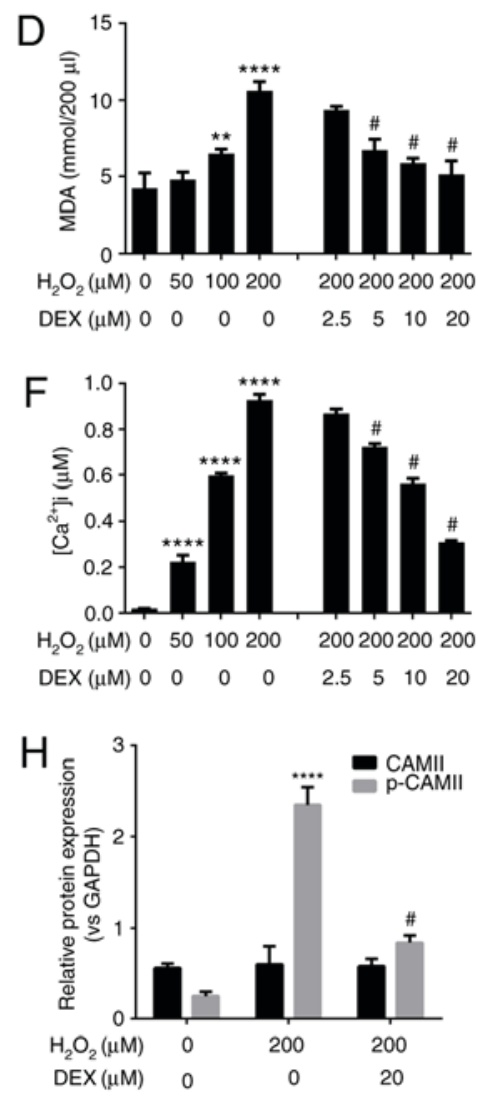

Figure 1. DEX protects HN-h cells against $\mathrm{H}_{2} \mathrm{O}_{2}$-induced cytotoxicity. (A) MTT assay indicated that DEX prevents $\mathrm{H}_{2} \mathrm{O}_{2}$-induced cell death. (B) Flow cytometry analysis of cell apoptosis indicated that DEX inhibits $\mathrm{H}_{2} \mathrm{O}_{2}$-induced cell apoptosis. DEX inhibits $\mathrm{H}_{2} \mathrm{O}_{2}$-induced (C) release of LDH, (D) production of MDA, (E) production of ROS and (F) production of intracellular $\mathrm{Ca}^{2+}$. (G) Western blot analysis indicated that DEX inhibits $\mathrm{H}_{2} \mathrm{O}_{2}$-induced phosphorylation of CAMII. (H) Densitometry analysis of bands obtained from western blot analysis. The experiments were performed three times in duplicate. "P $<0.05$, ${ }^{* *} \mathrm{P}<0.01,{ }^{* * * *} \mathrm{P}<0.001,{ }^{* * * * *} \mathrm{P}<0.0001$ vs. the control group (DEX=0 $\left.\mu \mathrm{M}, \mathrm{H}_{2} \mathrm{O}_{2}=0 \mu \mathrm{M}\right)$; ${ }^{*} \mathrm{P}<0.05$ vs. the $200 \mu \mathrm{M} \mathrm{H}_{2} \mathrm{O}_{2}$ treatment group. DEX, dexmedetomidine; LDH, lactate dehydrogenase; MDA, malondialdehyde; ROS, reactive oxygen species; CAMII, calmodulin-2; p, phosphorylated; ns, not significant.

A

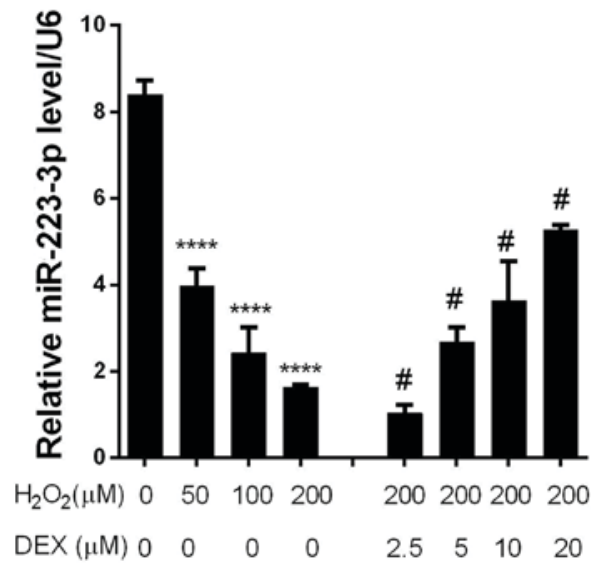

B

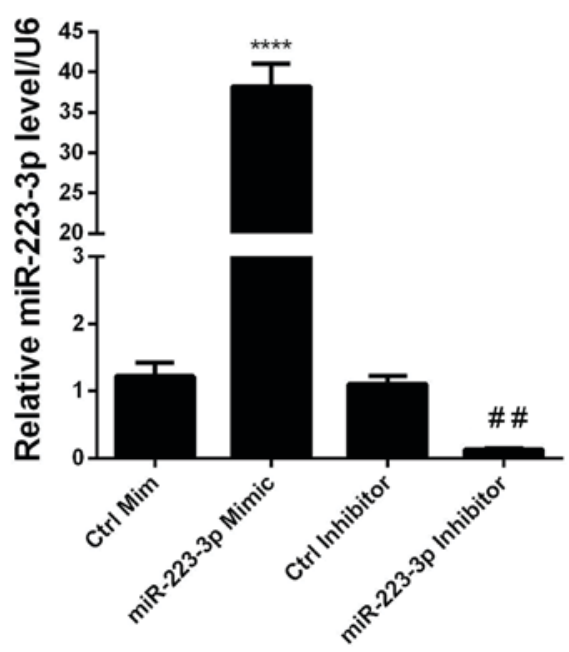

Figure 2. DEX prevents $\mathrm{H}_{2} \mathrm{O}_{2}$-mediated downregulation of miR-223-3p expression in $\mathrm{HN}$-h cells. (A) DEX prevents $\mathrm{H}_{2} \mathrm{O}_{2}$ mediated downregulation of miR-223-3p. ${ }^{* * * * *} \mathrm{P}<0.001$ vs. control untreated cells (DEX $=0 \mu \mathrm{M}, \mathrm{H}_{2} \mathrm{O}_{2}=0 \mu \mathrm{M}$ ); ${ }^{*} \mathrm{P}<0.05$ vs. the $200 \mu \mathrm{M} \mathrm{H}_{2} \mathrm{O}_{2}$ treatment group. (B) Transfection efficiency assessment. ${ }^{* * * * *} \mathrm{P}<0.001$ vs. mimic control, ${ }^{\# \#} \mathrm{P}<0.001$ vs. inhibitor control. Expression level of mir-223-3p measured using reverse transcription-quantitative polymerase chain reaction. Experiments were performed three times in duplicate. DEX, dexmedetomidine; miR, microRNA.

induced-cytotoxicity. To identify how miR-223-3p expression is involved in DEX-mediated protection of $\mathrm{HN}-\mathrm{H}$ cells against $\mathrm{H}_{2} \mathrm{O}_{2}$-induced cytotoxicity, $\mathrm{HN}-\mathrm{H}$ cells were transiently transfected with a miR-223-3p mimic or miR-223-3p inhibitor or their corresponding scrambled controls and treated or untreated with $\mathrm{H}_{2} \mathrm{O}_{2}$. Using RT-qPCR to detect the expression efficiency, 


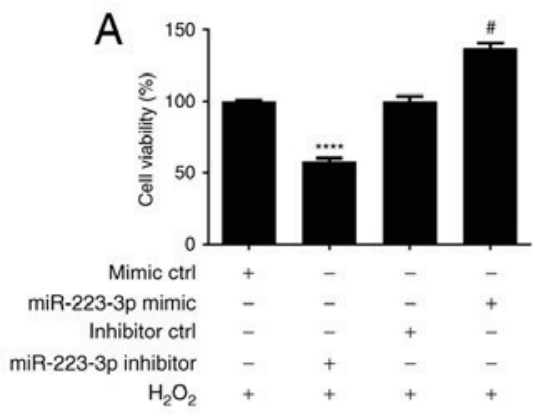

B
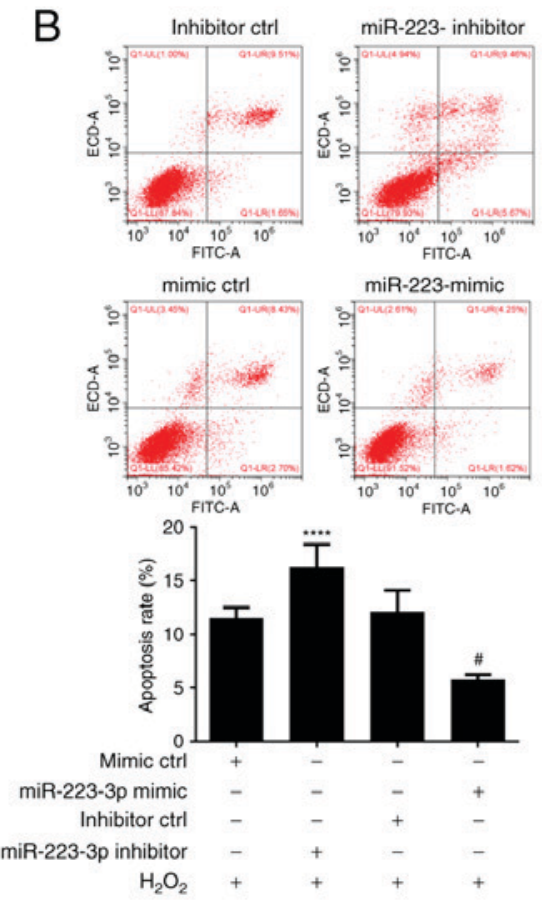

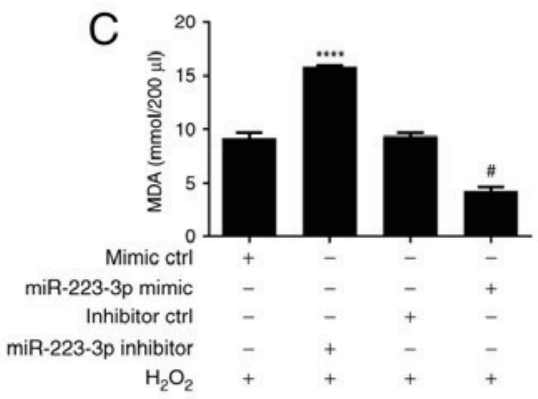

E

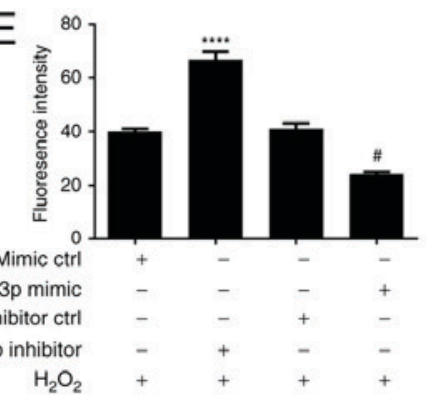

G
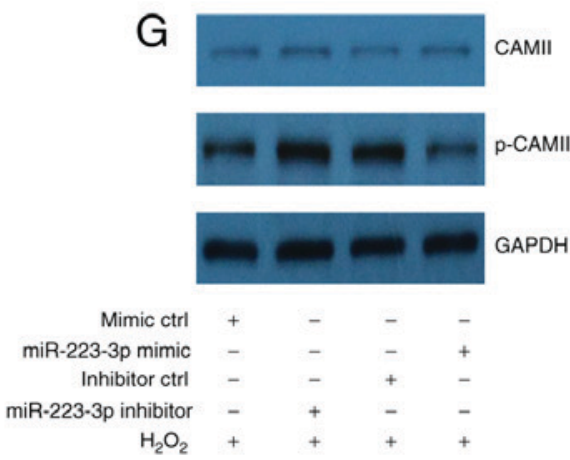
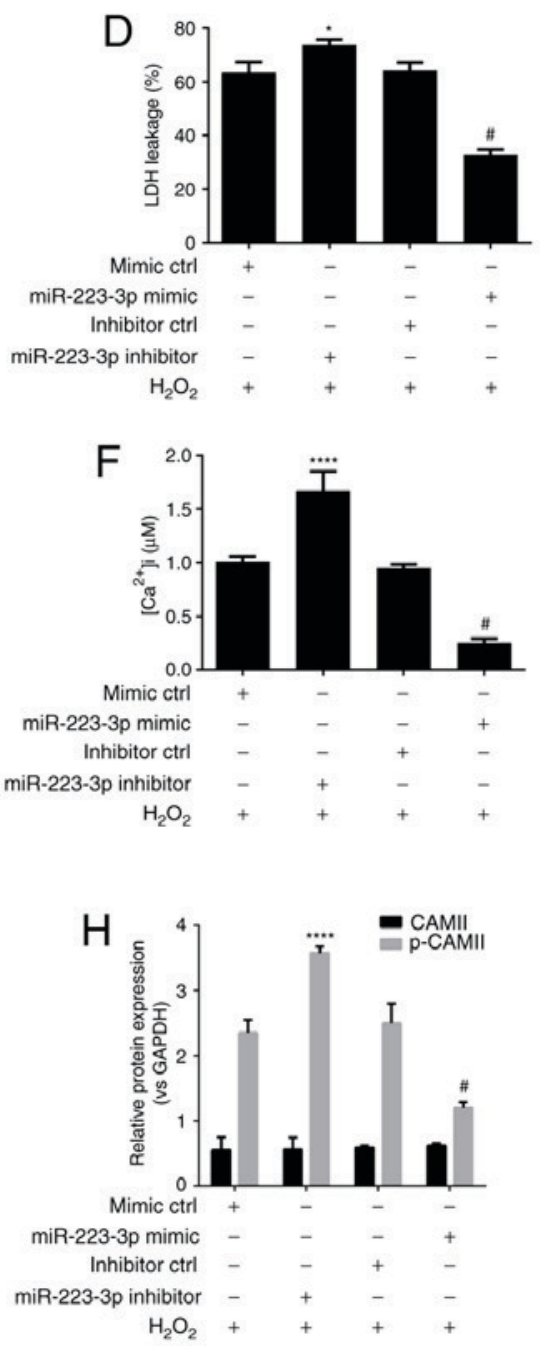

Figure 3. Upregulation of miR-223-3p expression is a mechanism involved in the neuroprotective effect of DEX against $\mathrm{H}_{2} \mathrm{O}_{2}$ induced-cytotoxicity. (A) MTT assay indicated that mir-223-3p overexpression reverses $\mathrm{H}_{2} \mathrm{O}_{2}$-induced cell death. (B) Flow cytometry analysis of cell apoptosis indicated that miR-223-3p overexpression inhibits $\mathrm{H}_{2} \mathrm{O}_{2}$-induced cell apoptosis. miR-223-3p overexpression inhibits $\mathrm{H}_{2} \mathrm{O}_{2}$-induced (C) production of $\mathrm{MDA}$, (D) release of $\mathrm{LDH}$, (E) production of ROS and (F) production of intracellular $\mathrm{Ca}^{2+}$. (G) Western blot analysis indicated that miR-223-3p overexpression inhibits $\mathrm{H}_{2} \mathrm{O}_{2}$-induced phosphorylation of CAMII. (H) Densitometry analysis of bands obtained from western blot analysis. Experiments were performed three times in duplicate. ${ }^{*} \mathrm{P}<0.05,{ }^{* * * * *} \mathrm{P}<0.001$ vs. the inhibitor control group $\left(\mathrm{H}_{2} \mathrm{O}_{2}=200 \mu \mathrm{M}\right)$; ${ }^{*} \mathrm{P}<0.05$ vs. the mimic control group $\left(200 \mu \mathrm{M} \mathrm{H}_{2} \mathrm{O}_{2}\right)$. DEX, dexmedetomidine; LDH, lactate dehydrogenase; MDA, malondialdehyde; ROS, reactive oxygen species; CAMII, calmodulin-2; miR, microRNA; ns, not significant.

it was observed that transfection with the miR-223-3p mimic effectively led to the overexpression of mir-223-3p whereas the transfection with mir-223-3p inhibitor led to significantly downregulated expression of mir-223-3p (Fig. 2B). The results of MTT and flow cytometry assays demonstrated that miR-223-3p inhibitor promoted $\mathrm{H}_{2} \mathrm{O}_{2}$-induced $\mathrm{HN}-\mathrm{H}$ cell death and apoptosis (Fig. 3A and B). By contrast, HN-H cell death and apoptosis were markedly inhibited following transfection with miR-223-3p mimics (Fig. 3A and B). No significant differences were identified between the negative controls. Similarly, the results indicated that miR-223-3p mimics significantly inhibited the LDH leakage, MDA release, ROS production, $\mathrm{Ca}^{2+}$ levels and CAMII phosphorylation (Fig. 3C-H, respectively). The aforementioned results suggested that activation of miR-223-3p led to neuroprotective effects.

TIAL1 is a direct target gene for mir-223-3p in HN-H cells. Bioinformatics analysis indicated TIAL1 as a potential target gene for miR-223-3p (Fig. 4A). Due to its involvement in cytotoxicity, the authors of the present study selected TIAL1 for further investigation. The protein expression level of TIAL1 was determined in HN-H cells following treatment with different concentrations of $\mathrm{H}_{2} \mathrm{O}_{2}$ and DEX by western blot analysis. Expression of TIAL1 was significantly enhanced by $\mathrm{H}_{2} \mathrm{O}_{2}$ and inhibited by treatment with DEX in a dose-dependent manner (Fig. 4B). To determine whether TIAL1 is a target gene of miR-223-3p in HN-H cells, the effect of mir-223-3p mimic or inhibitor was investigated. miR-223-3p mimics significantly inhibited the expression of TIAL1 while miR-223-3p inhibitor increased expression levels of TIAL1 in cultured HN-h cells (Fig. 4C). The aforementioned results suggested that TIAL1 was positively regulated by miR-223-3p. To confirm the direct binding of miR-223-3p to TIAL1, a luciferase reporter assay was performed. miR-223-3p mimic significantly decreased luciferase activity, while treatment with miR-223-3p inhibitor 
A
Position 918-924 of TIAL1 3' UTR 5' ...GAUCAGAAUGUUAAGACUGACAU... hsa-miR-223-3p 3' ...ACCCCAUAAACUGUUUGACUGU...

\section{Position 918-924 of TIAL1 3' UTR-MUT 5' ...GAUCAGAAUGUUGCAGTGAAU...}

B

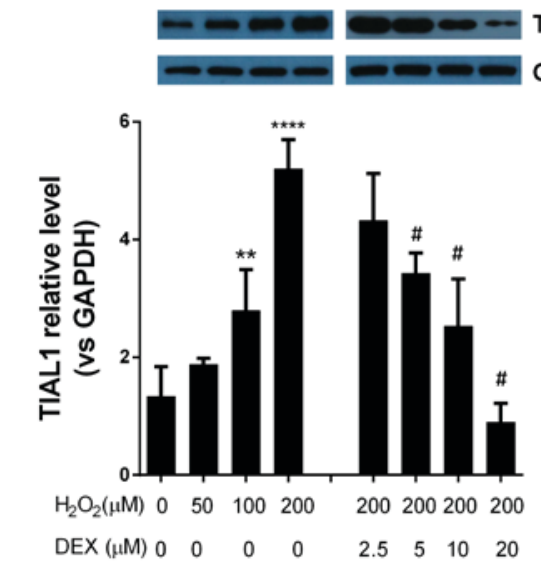

C TIAL1 GAPDH
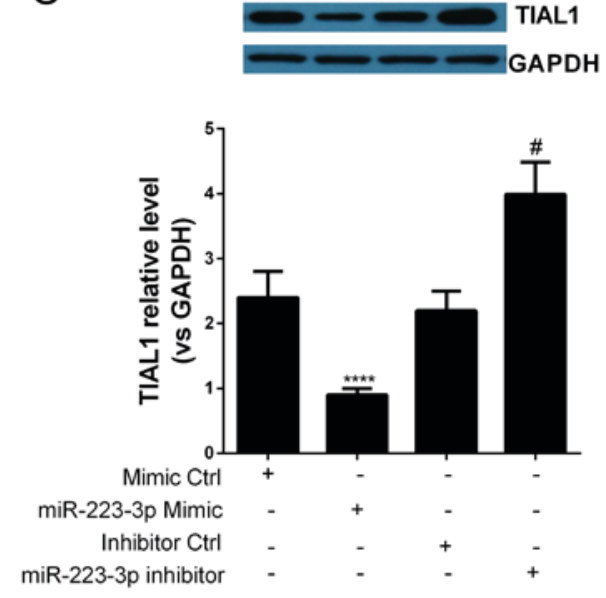

AL1 GAPDH
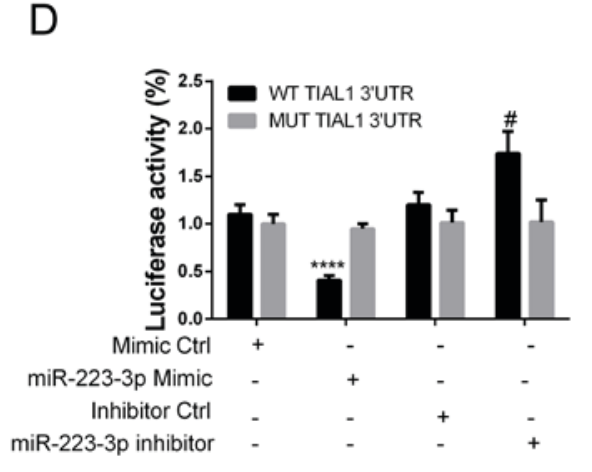

E

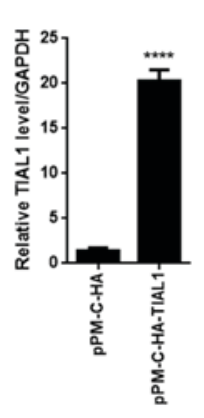

$\mathrm{F}$

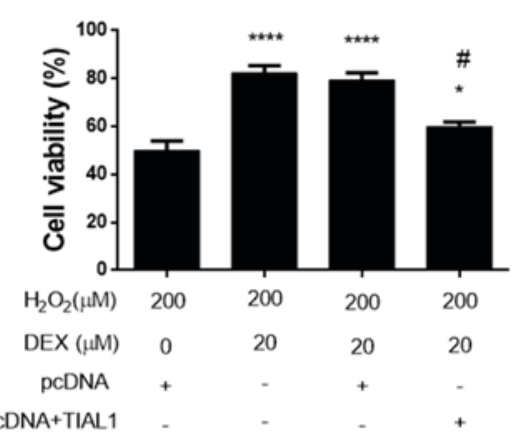

Figure 4. TIAL1 is a direct target of miR-223-3p in HN-H cells. (A) Bioinformatics analysis predicted the 3'-UTR of TIAL1 to be a putative seed sequence of miR-223-3p. (B) Western blot analysis indicated that DEX inhibited $\mathrm{H}_{2} \mathrm{O}_{2}$-induced TIAL1 expression. ${ }^{* * *} \mathrm{P}<0.01,{ }^{* * * * *} \mathrm{P}<0.0001$ vs. control untreated cells (DEX $=0 \mu \mathrm{M}$, $\mathrm{H}_{2} \mathrm{O}^{2}=0 \mu \mathrm{M}$ ); ${ }^{*} \mathrm{P}<0.05$ vs. the $200 \mu \mathrm{M} \mathrm{H}_{2} \mathrm{O}_{2}$ treatment group. (C) miR-223-3p overexpression inhibits TIAL1 expression. ${ }^{* * * * *} \mathrm{P}<0.0001 \mathrm{vs}$. control mimic; ${ }^{*} \mathrm{P}<0.05$ vs. control inhibitor group. (D) Luciferase assay indicated that TIAL1 is a direct target of mir-223-3p. ${ }^{* * * * *} \mathrm{P}<0.0001$ vs. control mimic; ${ }^{*} \mathrm{P}<0.05 \mathrm{vs}$. control inhibitor group. (E) Transfection efficiency assessment. ${ }^{* * * * *} \mathrm{P}<0.0001$ vs. control vector. (F) Overexpression of TIAL1 abrogated the effect of DEX on cell viability. $\mathrm{P}<0.05$, ${ }^{* * * * * *} \mathrm{P}<0.0001$ vs. control cells (DEX $=0 \mu \mathrm{M}, \mathrm{H}_{2} \mathrm{O}_{2}=200 \mu \mathrm{M}$, pcDNA vector); ${ }^{*} \mathrm{P}<0.05$ vs. the TIAL1 vector group (DEX=0 $\mu \mathrm{M}, \mathrm{H}_{2} \mathrm{O}_{2}=200 \mu \mathrm{M}$, pcDNA+TIAL1 vector). The experiments were performed three times in duplicate. DEX, dexmedetomidine; TIAL1, TIA1 cytotoxic granule associated RNA binding protein like 1; miR, microRNA; UTR, untranslated region; NS, not significant; miR, microRNA.

led to increased luciferase activity in cells transfected with a wild type TIAL1 3'-UTR vector. No significant differences were recorded between cells cotransfected with TIAL1 3'-UTR MUT vector and miR-223-3p mimic, inhibitor or control miRs (Fig. 4D). The aforementioned results indicated that TIAL1 mRNA 3'-UTR is a direct target of miR-223-3p.

Overexpression of TIALI abrogated the neuroprotective effect of DEX. To investigate whether DEX-induced TIAL1 inhibition mediates the neuroprotective effect, TIAL1 was overexpressed in HN-h cells and cell viability was measured following treatment with $\mathrm{H}_{2} \mathrm{O}_{2}$ and DEX. The transfection of TIAL1 vector allowed the effective overexpression of TIAL1 compared with control vector (Fig. 4E). The results indicated that overexpression of TIAL1 significantly decreased the effect of DEX on $\mathrm{H}_{2} \mathrm{O}_{2}$-induced cell death (Fig. 4F). The results of the present study indicated that DEX exerts neuroprotective effects via upregulation of miR-223-3p and subsequent downregulation of TIAL1.

\section{Discussion}

Anesthetics are vital for protection of the central nervous system during surgery. Administration of neuroprotective anesthetic drugs is a relevant approach for improving overall neurological outcomes of surgical procedures. Therefore, understanding of the protective properties of various anesthetic agents and elucidating the underlying molecular mechanisms is crucial for adequate selection of appropriate anesthetic treatments.

In the present study, DEX protected HN-h cells against $\mathrm{H}_{2} \mathrm{O}_{2}$-induced neurotoxicity by inhibiting cell apoptosis, decreasing LDH activity, MDA content, ROS production and calcium levels as indicated by the decrease in intracellular 
production of $\mathrm{Ca}^{2+}$ and phosphorylation of CAMII. The results of the present study are consistent with previous studies that demonstrated the neuroprotective effects of DEX. A previous study demonstrated that DEX exhibits neuroprotective effects on ischemia reperfusion by inhibiting apoptosis (25). In vitro data indicated that DEX prevents cultured hippocampal neurons from propofol-induced neurotoxicity by modulating the cyclic AMP-responsive element-binding protein, apoptosis regulator B cell lymphoma-2 and brain-derived neurotrophic factor (BDNF) signaling pathways (26). DEX has been reported to protect from focal cerebral ischemia reperfusion damage by inhibiting the nuclear factor-kB signaling pathway and to protect against traumatic brain injury $(1,27)$. Previous reports have demonstrated that DEX induces neuroprotective effects by promoting BDNF expression in astrocytes via regulation of the ERK signaling pathway (28). However, the molecular mechanism underlying the neuroprotective effect of DEX remains to be elucidated.

miRs in the nervous system are associated with neuronal survival and control of the accumulation of toxic proteins associated with neurodegeneration (29-34). miR-223 is a regulatory factor involved in differentiation of immature neurons (35). Furthermore, a previous study has demonstrated that miR-223 exerts neuroprotective effects through glutamate receptors GluR2 and NR2B (36). However, whether the neuroprotective effect of DEX is mediated by regulation of miR-223-3p remains to be elucidated. In the present study, treatment with $\mathrm{H}_{2} \mathrm{O}_{2}$ induced miR-223-3p downregulation in hippocampal neurons in a dose-dependent manner. Treatment of $\mathrm{H}_{2} \mathrm{O}_{2}$-pretreated $\mathrm{HN}$-h cells with DEX markedly increased miR-223-3p expression in a dose-dependent manner. The results of the present study indicated that upregulation of miR-223-3p expression represents a mechanism involved in the neuroprotective effect of DEX against $\mathrm{H}_{2} \mathrm{O}_{2}$ induced-neurotoxicity. The present study also demonstrated that overexpression of miR-223-3p resulted in inhibition of $\mathrm{H}_{2} \mathrm{O}_{2}$-induced apoptosis of $\mathrm{HN}$-h cells. The luciferase reporter assay demonstrated that TIAL1 gene is a direct target of miR-223-3p in HN-h cells. Overexpression of TIAL1 abrogated the neuroprotective effect of DEX on $\mathrm{H}_{2} \mathrm{O}_{2}$-induced neurotoxicity. To the best of the authors knowledge, the present study is the first to demonstrate that DEX exerts neuroprotective effects by downregulating TIAL1 via activation of miR-223-3p in hippocampal neuronal cells in vitro.

Apoptosis, an autonomous, genetically controlled cell death, contributes to selective elimination of cells in physiological and pathological conditions. In the present study, DEX and miR-223-3p demonstrated a protective effect against $\mathrm{H}_{2} \mathrm{O}_{2}$-induced apoptosis in $\mathrm{HN}-\mathrm{H}$ cells. The results of the present study suggested that apoptosis was involved in the neuroprotective mechanism of DEX and that the effect of DEX may have been mediated by the miR-223-3p/TIAL1 interaction.

Calcium is an important signal transducer in nerve cells. The present study aimed to determine whether intracellular calcium homeostasis could be influenced by treatment with DEX and associated upregulation of miR-223-3p. $\mathrm{H}_{2} \mathrm{O}_{2}$-induced increase in $\mathrm{Ca}^{2+}$ levels was significantly decreased by treatment with DEX and overexpression of miR-223-3p. The aforementioned results indicated that DEX may disrupt intracellular calcium levels by increasing $\mathrm{Ca}^{2+}$ levels in hippocampal cells and that calcium signaling may serve an important role in apoptosis.

In conclusion, the present study demonstrated that DEX exerts neuroprotective effects on hippocampal neuronal cells in vitro by downregulating TIAL1 via activation of miR-223-3p. It was also demonstrated that, in the present study, apoptosis and ROS and calcium overload were regulated by treatment with DEX. The results of the present study contribute to the understanding of the molecular mechanism underlying DEX-mediated neuroprotection. Manipulation of miR-223-3p/TAL1 interaction can in the future influence application of DEX in anesthesia.

\section{Acknowledgements}

Not applicable.

\section{Funding}

No funding was received.

\section{Availability of data and materials}

All data generated or analyzed during this study are included in this published article.

\section{Authors' contributions}

QW, HY, HMY, MM, YM and RL all participated in the conception and design of the study. QW and HY performed the experiments. QW, HY, HMY, MM and YM analyzed the data. QW wrote the manuscript.

\section{Ethics approval and consent to participate}

Not applicable.

\section{Patient consent for publication}

Not applicable.

\section{Competing interests}

The authors declare that they have no competing interests.

\section{References}

1. Wang L, Liu H, Zhang L, Wang G, Zhang M and Yu Y: Neuroprotection of dexmedetomidine against cerebral ischemia-reperfusion injury in rats: Involved in inhibition of $\mathrm{NF}-\kappa \mathrm{B}$ and inflammation response. Biomol Ther (Seoul) 25: 383-389, 2017.

2. Fu C, Dai X, Yang Y, Lin M, Cai Y and Cai S: Dexmedetomidine attenuates lipopolysaccharide-induced acute lung injury by inhibiting oxidative stress, mitochondrial dysfunction and apoptosis in rats. Mol Med Rep 15: 131-138, 2017.

3. Küçükebe ÖB, Özzeybek D, Abdullayev R, Ustaoğlu A, Tekmen I and Küme T: Effect of dexmedetomidine on acute lung injury in experimental ischemia-reperfusion model. Rev Bras Anestesiol 67: 139-146, 2017 (In Portuguese).

4. Shen J, Fu G, Jiang L, Xu J, Li L and Fu G: Effect of dexmedetomidine pretreatment on lung injury following intestinal ischemia-reperfusion. Exp Ther Med 6: 1359-1364, 2013. 
5. Xie C, Li Y, Liang J, Xiao J, Zhao Z and Li T: The effect of dexmedetomidine on autophagy and apoptosis in intestinal ischemia reperfusion-induced lung injury. Zhonghua Jie $\mathrm{He} \mathrm{He}$ Hu Xi Za Zhi 38: 761-764, 2015 (In Chinese).

6. Ammar AS, Mahmoud KM, Kasemy ZA and Helwa MA: Cardiac and renal protective effects of dexmedetomidine in cardiac surgeries: A randomized controlled trial. Saudi J Anaesth 10 395-401, 2016.

7. Cakir M, Polat A, Tekin S, Vardi N, Taslidere E, Rumeysa Duran $\mathrm{Z}$ and Tanbek K: The effect of dexmedetomidine against oxidative and tubular damage induced by renal ischemia reperfusion in rats. Ren Fail 37: 704-708, 2015.

8. de Carvalho AL, Vital RB, Kakuda CM, Braz JR, Castiglia YM, Braz LG, Módolo MP, Ribeiro OR, Domingues MA and Módolo NS: Dexmedetomidine on renal ischemia-reperfusion injury in rats: Assessment by means of NGAL and histology. Ren Fail 37: 526-530, 2015.

9. Liu YE, Tong CC, Zhang YB, Jin HX, Gao Y and Hou MX: Effect of dexmedetomidine on rats with renal ischemia-reperfusion injury and the expression of tight junction protein in kidney. Int J Clin Exp Med 8: 18751-18757, 2015.

10. Si YN, Bao HG, Xu L, Wang XL, Shen Y, Wang JS and Yang XB: Dexmedetomidine protects against ischemia/reperfusion injury in rat kidney. Eur Rev Med Pharmacol Sci 18 : 1843-1851, 2014.

11. Zhang XK, Zhou XP, Zhang Q and Zhu F: The preventive effects of dexmedetomidine against intestinal ischemia-reperfusion injury in Wistar rats. Iran J Basic Med Sci 18: 604-609, 2015.

12. Zhang XY, Liu ZM, Wen SH, Li YS, Li Y, Yao X, Huang WQ and Liu KX: Dexmedetomidine administration before, but not after, ischemia attenuates intestinal injury induced by intestinal ischemia-reperfusion in rats. Anesthesiology 116: 1035-1046, 2012.

13. Akpınar H, Nazıroğlu M, Övey İS, Çiğ B and Akpınar O: The neuroprotective action of dexmedetomidine on apoptosis, calcium entry and oxidative stress in cerebral ischemia-induced rats: Contribution of TRPM2 and TRPV1 channels. Sci Rep 6 : 37196, 2016.

14. Tanabe K, Matsushima-Nishiwaki R, Kozawa O and Iida $\mathrm{H}$ : Dexmedetomidine suppresses interleukin- $1 \beta$-induced interleukin-6 synthesis in rat glial cells. Int J Mol Med 34: 1032-1038, 2014

15. Zhu YM, Wang CC, Chen L, Qian LB, Ma LL, Yu J, Zhu MH, Wen CY, Yu LN and Yan M: Both PI3K/Akt and ERK1/2 pathways participate in the protection by dexmedetomidine against transient focal cerebral ischemia/reperfusion injury in rats. Brain Res 1494: 1-8, 2013.

16. Chaudhuri AD, Choi DC, Kabaria S, Tran A and Junn E MicroRNA-7 regulates the function of mitochondrial permeability transition pore by targeting VDAC1 expression. J Biol Chem 291: 6483-6493, 2016.

17. Ma Q, Dasgupta C, Li Y, Bajwa NM, Xiong F, Harding B, Hartman $R$ and Zhang L: Inhibition of microRNA-210 provides neuroprotection in hypoxic-ischemic brain injury in neonatal rats. Neurobiol Dis 89: 202-212, 2016.

18. Quinlan S and Jimenez-Mateos EM: Can we protect the brain via preconditioning? Role of microRNAs in neuroprotection. Neural Regen Res 11: 388-389, 2016.

19. Ren L, Zhu R and Li X: Silencing miR-181a produces neuroprotection against hippocampus neuron cell apoptosis post-status epilepticus in a rat model and in children with temporal lobe epilepsy. Genet Mol Res 15, 2016.
20. Sinoy S, Fayaz SM, Charles KD, Suvanish VK, Kapfhammer JP and Rajanikant GK: Amikacin inhibits miR-497 maturation and exerts post-ischemic neuroprotection. Mol Neurobiol 54: 3683-3694, 2017.

21. Zhou X, Su S, Li S, Pang X, Chen C, Li J and Liu J: MicroRNA-146a down-regulation correlates with neuroprotection and targets pro-apoptotic genes in cerebral ischemic injury in vitro. Brain Res 1648: 136-143, 2016.

22. Li M, He Y, Zhou Z, Ramirez T, Gao Y, Gao Y, Ross RA, Cao H, Cai Y, Xu M, et al: MicroRNA-223 ameliorates alcoholic liver injury by inhibiting the IL-6-p47 ${ }^{\text {phox }}$-oxidative stress pathway in neutrophils. Gut, 2016.

23. Shin JH, Park YM, Kim DH, Moon GJ, Bang OY, Ohn T and Kim HH: Ischemic brain extract increases SDF-1 expression in astrocytes through the CXCR2/miR-223/miR-27b pathway. Biochim Biophys Acta 1839: 826-836, 2014.

24. Livak KJ and Schmittgen TD: Analysis of relative gene expression data using real-time quantitative PCR and the 2(-Delta Delta C(T)) method. Methods 25: 402-408, 2001

25. Wu GJ, Chen JT, Tsai HC, Chen TL, Liu SH and Chen RM: Protection of dexmedetomidine against ischemia/reperfusion-induced apoptotic insults to neuronal cells occurs via an intrinsic mitochondria-dependent pathway. J Cell Biochem 118: 2635-2644, 2017.

26. Wei Y, Hu J, Liang Y, Zhong Y, He D, Qin Y, Li L, Chen J, Xiao Q and Xie Y: Dexmedetomidine pretreatment attenuates propofol-induced neurotoxicity in neuronal cultures from the rat hippocampus. Mol Med Rep 14: 3413-3420, 2016.

27. Schoeler M, Loetscher PD, Rossaint R, Fahlenkamp AV, Eberhardt G, Rex S, Weis J and Coburn M: Dexmedetomidine is neuroprotective in an in vitro model for traumatic brain injury. BMC Neurol 12: 20, 2012.

28. Degos V, Charpentier TL, Chhor V, Brissaud O, Lebon S, Schwendimann L, Bednareck N, Passemard S, Mantz J and Gressens P: Neuroprotective effects of dexmedetomidine against glutamate agonist-induced neuronal cell death are related to increased astrocyte brain-derived neurotrophic factor expression. Anesthesiology 118: 1123-1132, 2013.

29. Eacker SM, Dawson TM and Dawson VL: Understanding microRNAs in neurodegeneration. Nat Rev Neurosci 10: 837-841, 2009.

30. Singh SK: miRNAs: From neurogeneration to neurodegeneration. Pharmacogenomics 8: 971-978, 2007.

31. Bushati N and Cohen SM: MicroRNAs in neurodegeneration. Curr Opin Neurobiol 18: 292-296, 2008.

32. Karnati HK, Panigrahi MK, Gutti RK, Greig NH and Tamargo IA: miRNAs: Key players in neurodegenerative disorders and epilepsy. J Alzheimers Dis 48: 563-580, 2015.

33. Kamal MA, Mushtaq G and Greig NH: Current update on synopsis of miRNA dysregulation in neurological disorders. CNS Neurol Disord Drug Targets 14: 492-501, 2015.

34. Goodall EF, Heath PR, Bandmann O, Kirby J and Shaw PJ: Neuronal dark matter: The emerging role of microRNAs in neurodegeneration. Front Cell Neurosci 7: 178, 2013.

35. Harraz MM, Xu JC, Guiberson N, Dawson TM and Dawson VL: MiR-223 regulates the differentiation of immature neurons. Mol Cell Ther 2: 18, 2014

36. Harraz MM, Eacker SM, Wang X, Dawson TM and Dawson VL: MicroRNA-223 is neuroprotective by targeting glutamate receptors. Proc Natl Acad Sci USA 109: 18962-18967, 2012.

This work is licensed under a Creative Commons Attribution-NonCommercial-NoDerivatives 4.0 International (CC BY-NC-ND 4.0) License. 